\title{
Molecular Dynamics Simulation of the
}

\section{n-Octacosane-Water Mixture Confined in Graphene}

\section{Mesopores: Comparison of Atomistic and Coarse-}

\section{Grained Calculations and the Effect of Catalyst}

\section{Nanoparticle}

Konstantinos D. Papavasileiou, ${ }^{1,2}$ Loukas D. Peristeras, ${ }^{1}$ Andreas Bick, ${ }^{2}$ and Ioannis G. Economou ${ }^{1,3, *}$

\footnotetext{
${ }^{1}$ National Center for Scientific Research "Demokritos", Institute of Nanoscience and Nanotechnology, Molecular Thermodynamics and Modelling of Materials Laboratory, GR-15310 Aghia Paraskevi Attikis, Greece

${ }^{2}$ Scienomics SARL, 16 rue de l' Arcade, 75008, Paris, France

${ }^{3}$ Texas A\&M University at Qatar, Chemical Engineering Program, Education City, PO Box 23874, Doha, Qatar
}

*To whom correspondence should be addressed

IGE: ioannis.economou@qatar.tamu.edu 
Table S1. Density of bulk $n-\mathrm{C}_{28}, \mathrm{H}_{2} \mathrm{O}$ and $n-\mathrm{C}_{28}-\mathrm{H}_{2} \mathrm{O}$ mixture at $473 \mathrm{~K}$ and $3.4 \mathrm{MPa}$ from the AA and CG simulations. Statistical uncertainty is provided as $95 \%$ confidence intervals. Experimental values for the pure $n-\mathrm{C}_{28}$ and $\mathrm{H}_{2} \mathrm{O}$ are retrieved from the DIPPR ${ }^{1}$ and NIST databases, ${ }^{2}$ respectively.

\begin{tabular}{l|c|c}
\hline \multirow{2}{*}{\multicolumn{1}{c|}{ Bulk system }} & \multicolumn{2}{|c}{ Density $\left(\mathrm{kg} \mathrm{m}^{-3}\right)$} \\
\cline { 2 - 3 } & Simulation & Experiment \\
\hline$n-\mathrm{C}_{28}$ & AA & $696^{1}$ \\
$\mathrm{H}_{2} \mathrm{O}$ & $707 \pm 7$ & $866^{2}$ \\
$n-\mathrm{C}_{28}$ in $n-\mathrm{C}_{28}-\mathrm{H}_{2} \mathrm{O}$ & $859 \pm 6$ & \\
$\mathrm{H}_{2} \mathrm{O}$ in $n-\mathrm{C}_{28}-\mathrm{H}_{2} \mathrm{O}$ & $697 \pm 4$ & \\
\hline & $859 \pm 4$ & $696^{1}$ \\
\hline$n-\mathrm{C}_{28}$ & $731 \pm 2$ & $866^{2}$ \\
$\mathrm{H}_{2} \mathrm{O}$ & $814 \pm 4$ & \\
$n-\mathrm{C}_{28}$ in $n-\mathrm{C}_{28}-\mathrm{H}_{2} \mathrm{O}$ & $727 \pm 5$ & \\
$\mathrm{H}_{2} \mathrm{O}$ in $n-\mathrm{C}_{28}-\mathrm{H}_{2} \mathrm{O}$ & $814 \pm 1$ & \\
\hline
\end{tabular}

Table S2. IFT of the $n-\mathrm{C}_{28}-\mathrm{H}_{2} \mathrm{O}$ and $n-\mathrm{C}_{28}-\mathrm{H}_{2} \mathrm{O}-\mathrm{C}_{12} \mathrm{H}_{25} \mathrm{OH}$ bulk mixtures at $473.15 \mathrm{~K}$ and 3.4 MPa from the AA and CG simulations. Statistical uncertainty is provided as $95 \%$ confidence intervals. The IFT predictions for the bulk $n-\mathrm{C}_{28}-\mathrm{H}_{2} \mathrm{O}$ mixture by the Danesh ${ }^{3}$ correlation and the genetic programming (GP) method proposed by Rostami et al. ${ }^{4}$ are also illustrated.

\begin{tabular}{l|c|c|c|c}
\hline \multirow{2}{*}{ Bulk system } & \multicolumn{4}{c}{ IFT $\left(\mathrm{mN} \mathrm{m}^{-1}\right)$} \\
\cline { 2 - 5 } & \multicolumn{2}{|c|}{ Simulation } & \multicolumn{2}{c}{ IFT prediction } \\
\hline \multirow{3}{*}{$n-\mathrm{C}_{28}-\mathrm{H}_{2} \mathrm{O}$} & AA & CG & Danesh $^{3}$ & Rostami et al. $^{4}$ \\
$n-\mathrm{C}_{28}-\mathrm{H}_{2} \mathrm{O}-\mathrm{C}_{12} \mathrm{H}_{25} \mathrm{OH}$ & $37.1 \pm 0.2$ & $22.0 \pm 0.1$ & 36.9 & 43.3 \\
\hline
\end{tabular}


Table S3. Calculated $D_{\text {xy }}$ values $\left(\times 10^{9} \mathrm{~m}^{2} \mathrm{~s}^{-1}\right)$ of $n-\mathrm{C}_{28}$ and $\mathrm{H}_{2} \mathrm{O}$ in the $n-\mathrm{C}_{28}-\mathrm{H}_{2} \mathrm{O}$ and $n-\mathrm{C}_{28}-$ $\mathrm{H}_{2} \mathrm{O}-\mathrm{C}_{12} \mathrm{H}_{25} \mathrm{OH}$ mixtures confined in $\mathrm{G}$ and $\mathrm{GO}$ at $473 \mathrm{~K}$ and $3.4 \mathrm{MPa}$ from the $\mathrm{AA}$ and $\mathrm{CG}$ simulations.

\begin{tabular}{|c|c|c|c|c|}
\hline System & \multicolumn{4}{|c|}{ AA } \\
\hline Bulk & \multicolumn{2}{|c|}{$n-\mathrm{C}_{28}$} & \multicolumn{2}{|c|}{$\mathrm{H}_{2} \mathrm{O}$} \\
\hline$n-\mathrm{C}_{28}-\mathrm{H}_{2} \mathrm{O}$ & \multicolumn{2}{|c|}{$3.0 \pm 0.2$} & \multicolumn{2}{|c|}{$20.5 \pm 0.4$} \\
\hline $\mathrm{G}$ & Region 1 & Region 2 & Region 1 & Region 2 \\
\hline$n-\mathrm{C}_{28}-\mathrm{H}_{2} \mathrm{O}$ & $2.4 \pm 0.1$ & $3.5 \pm 0.1$ & - & $20.3 \pm 0.6$ \\
\hline$n-\mathrm{C}_{28}-\mathrm{H}_{2} \mathrm{O}-\mathrm{C}_{12} \mathrm{H}_{25} \mathrm{OH}$ & $2.4 \pm 0.4$ & $3.3 \pm 0.1$ & - & $19.7 \pm 0.3$ \\
\hline \multicolumn{5}{|l|}{ GO } \\
\hline$n-\mathrm{C}_{28}-\mathrm{H}_{2} \mathrm{O}$ & - & $2.8 \pm 0.1$ & $7.2 \pm 0.6$ & $20.9 \pm 0.2$ \\
\hline$n-\mathrm{C}_{28}-\mathrm{H}_{2} \mathrm{O}-\mathrm{C}_{12} \mathrm{H}_{25} \mathrm{OH}$ & - & $2.6 \pm 0.1$ & $7.1 \pm 0.6$ & $19.5 \pm 0.2$ \\
\hline & \multicolumn{4}{|c|}{$\mathrm{CG}$} \\
\hline Bulk & \multicolumn{2}{|c|}{$n-\mathrm{C}_{28}$} & \multicolumn{2}{|c|}{$\mathrm{H}_{2} \mathrm{O}$} \\
\hline$n-\mathrm{C}_{28}-\mathrm{H}_{2} \mathrm{O}$ & \multicolumn{2}{|c|}{$2.4 \pm 0.1$} & \multicolumn{2}{|c|}{$17.0 \pm 0.2$} \\
\hline $\mathrm{G}$ & Region 1 & Region 2 & Region 1 & Region 2 \\
\hline$n-\mathrm{C}_{28}-\mathrm{H}_{2} \mathrm{O}$ & $1.8 \pm 0.1$ & $2.3 \pm 0.1$ & - & $16.9 \pm 0.2$ \\
\hline$n-\mathrm{C}_{28}-\mathrm{H}_{2} \mathrm{O}-\mathrm{C}_{12} \mathrm{H}_{25} \mathrm{OH}$ & $1.9 \pm 0.1$ & $2.3 \pm 0.1$ & - & $15.7 \pm 0.1$ \\
\hline \multicolumn{5}{|l|}{ GO } \\
\hline$n-\mathrm{C}_{28}-\mathrm{H}_{2} \mathrm{O}$ & - & $2.2 \pm 0.1$ & $2.1 \pm 0.1$ & $17.5 \pm 0.1$ \\
\hline$n-\mathrm{C}_{28}-\mathrm{H}_{2} \mathrm{O}-\mathrm{C}_{12} \mathrm{H}_{25} \mathrm{OH}$ & - & $2.2 \pm 0.1$ & $2.4 \pm 0.2$ & $15.9 \pm 0.1$ \\
\hline
\end{tabular}

Table S4. Born-Huggins-Meyer (BHM) potential parameters obtained from the fit to the effective interaction energies $E_{\mathrm{int}}^{\mathrm{eff}}$ between Co with $n$-butane and the four water molecule cluster that represent the $\mathrm{C} 1$ and W MARTINI beads, respectively, at each averaged $r_{\mathrm{COM}}$. The $\mathrm{R}^{2}$ value of the fitting in both cases is equal to 0.9 .

\begin{tabular}{l|c|c|c|c|c}
\hline Interaction type & $\begin{array}{c}\mathrm{A} \\
\left(\mathrm{kJ} \mathrm{mol}^{-1}\right)\end{array}$ & $\begin{array}{c}\mathrm{B} \\
\left(\mathrm{nm}^{-1}\right)\end{array}$ & $\begin{array}{c}\mathrm{C} \\
\left(\mathrm{kJ} \mathrm{mol}^{-1} \mathrm{~nm}^{-6}\right)\end{array}$ & $\begin{array}{c}\mathrm{D} \\
\left(\mathrm{kJ} \mathrm{mol}^{-1} \mathrm{~nm}^{-8}\right)\end{array}$ & $\begin{array}{c}\sigma \\
(\mathrm{nm})\end{array}$ \\
\hline C1-Co bead & 86.12 & 22.49 & 0.05 & $7 \times 10^{-4}$ & 0.28 \\
W-Co bead & 68.33 & 18.78 & 0.07 & $3 \times 10^{-3}$ & 0.28 \\
\hline
\end{tabular}


a)

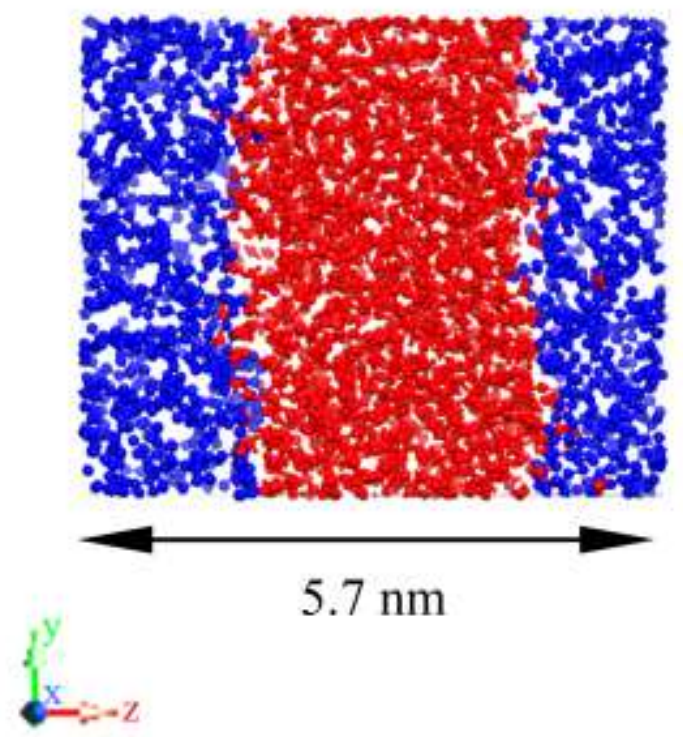

b)

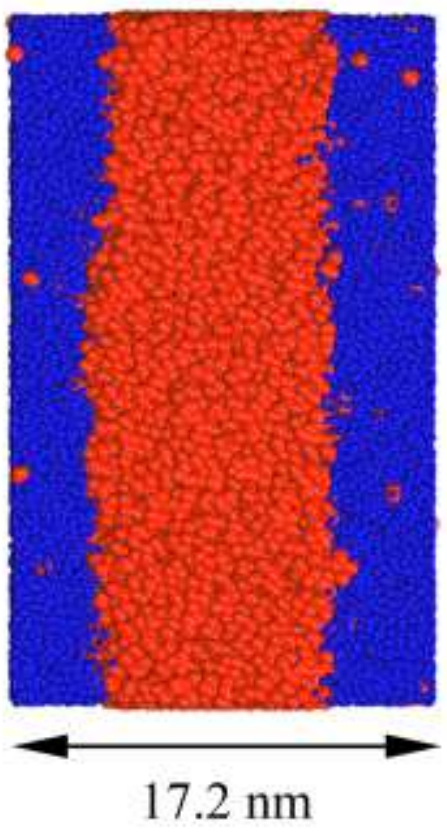

$17.2 \mathrm{~nm}$

Figure S1. Equilibrated structure of the $n-\mathrm{C}_{28}-\mathrm{H}_{2} \mathrm{O}$ mixture at $473 \mathrm{~K}$ and $3.4 \mathrm{MPa}$ from the AA and CG simulations. 
1

Co

(111)

a)
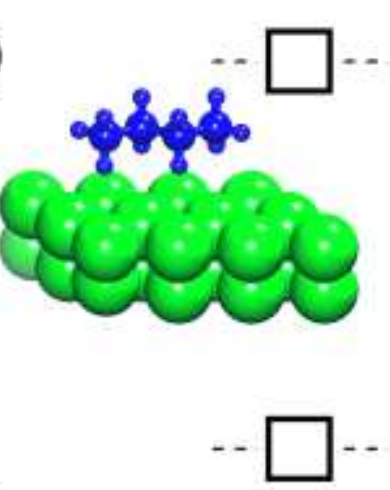

b)

(111)

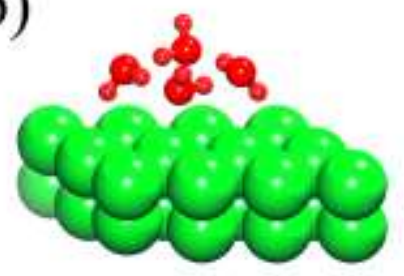

a)

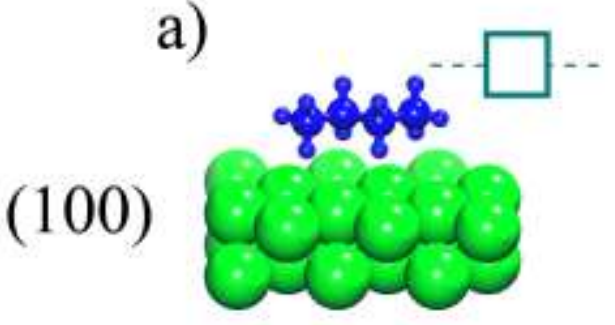

b)

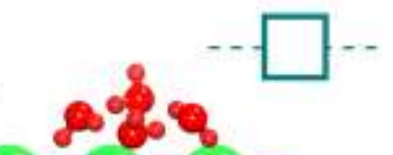

(100)

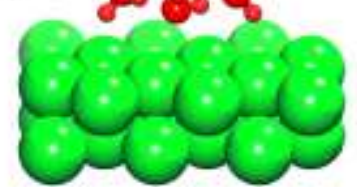

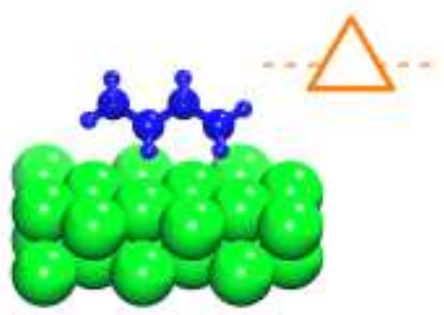
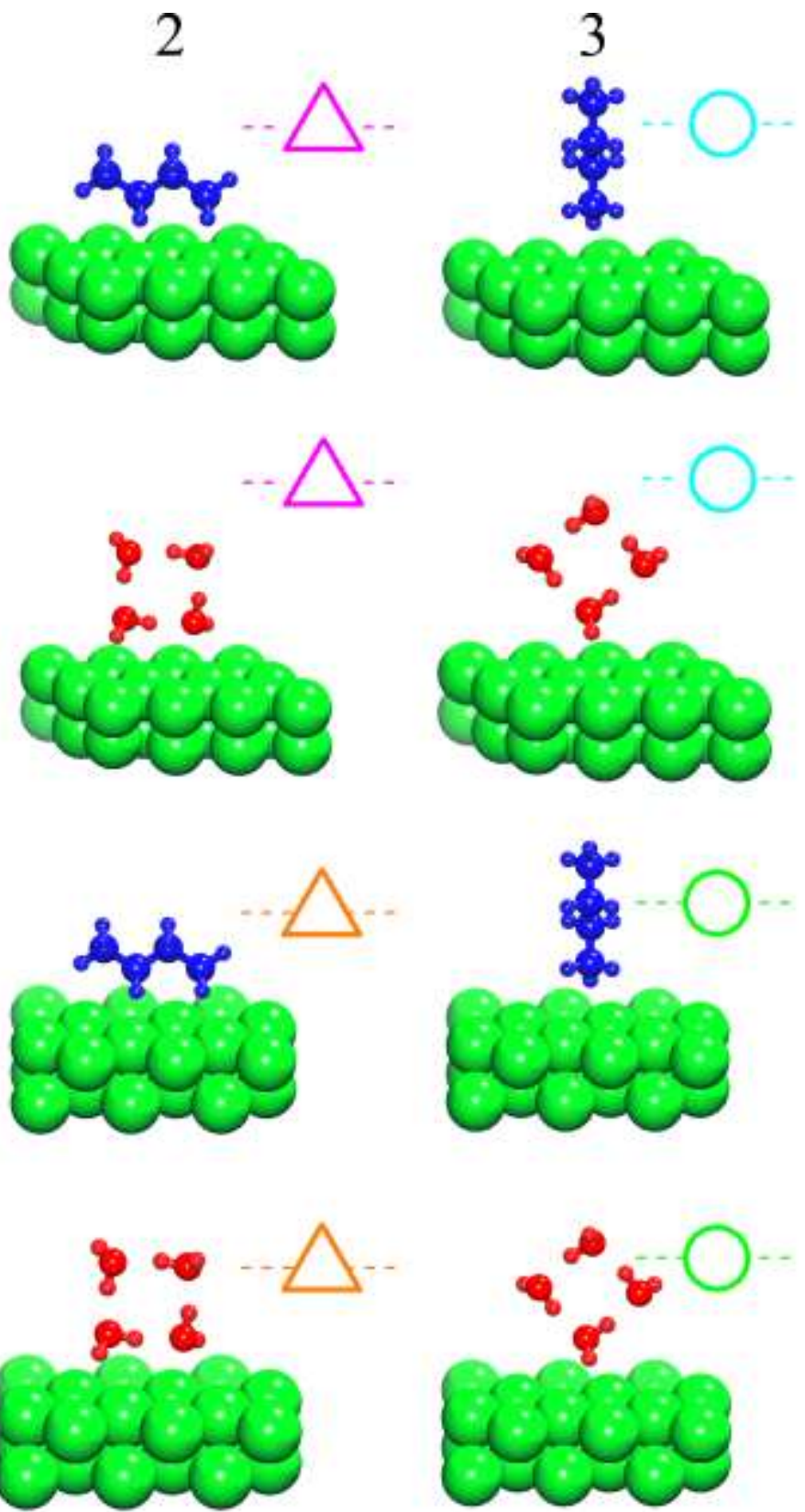

Figure S2. Clusters of $24 \mathrm{Co}(111)$ and (100) atoms with a) $n$-butane $\left(\mathrm{C}_{4} \mathrm{H}_{10}\right)$ and b) a four-water molecule cluster at the three different orientation examined. 


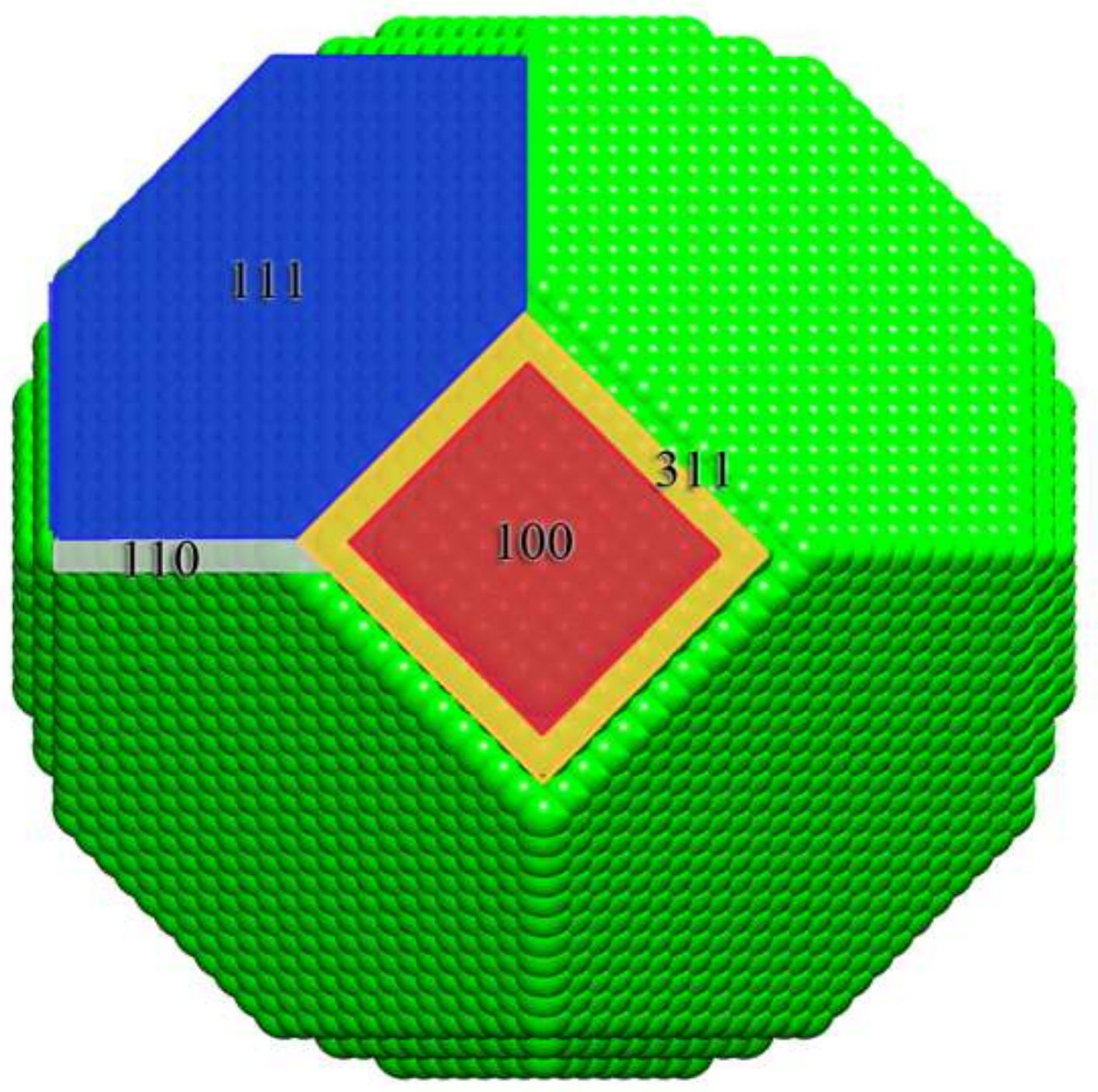

Figure S3. The fcc Co NP obtained by Wulff construction by means of the ASE software ${ }^{5}$ The four different facets namely (111), (100), (311) and (110), are also illustrated. 

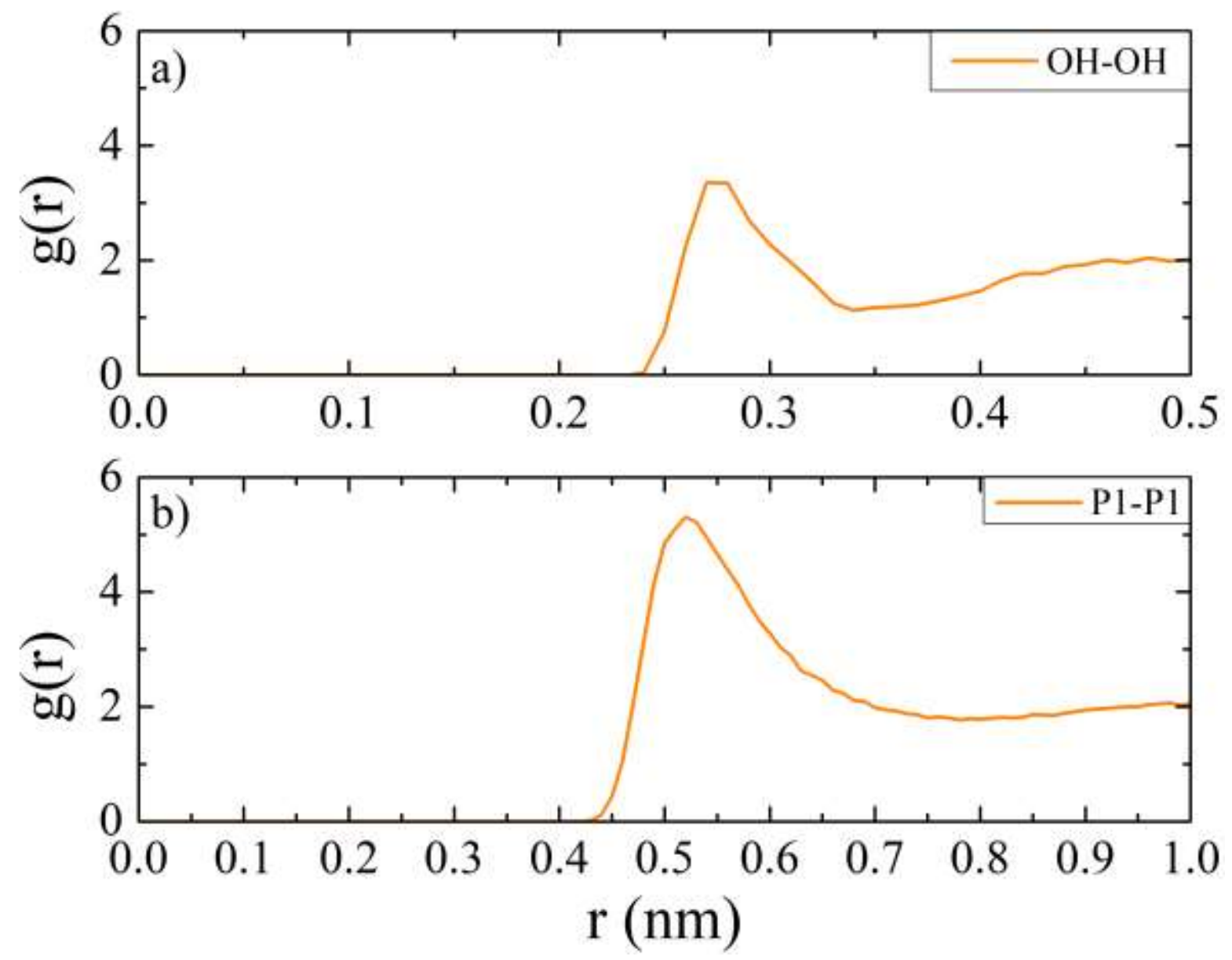

Figure S4. Interparticle RDFs of the (a) hydroxy $(\mathrm{OH})$ atoms and (b) P1 beads. The location of the minimum was used as the distance criterion for clustering evaluation. 


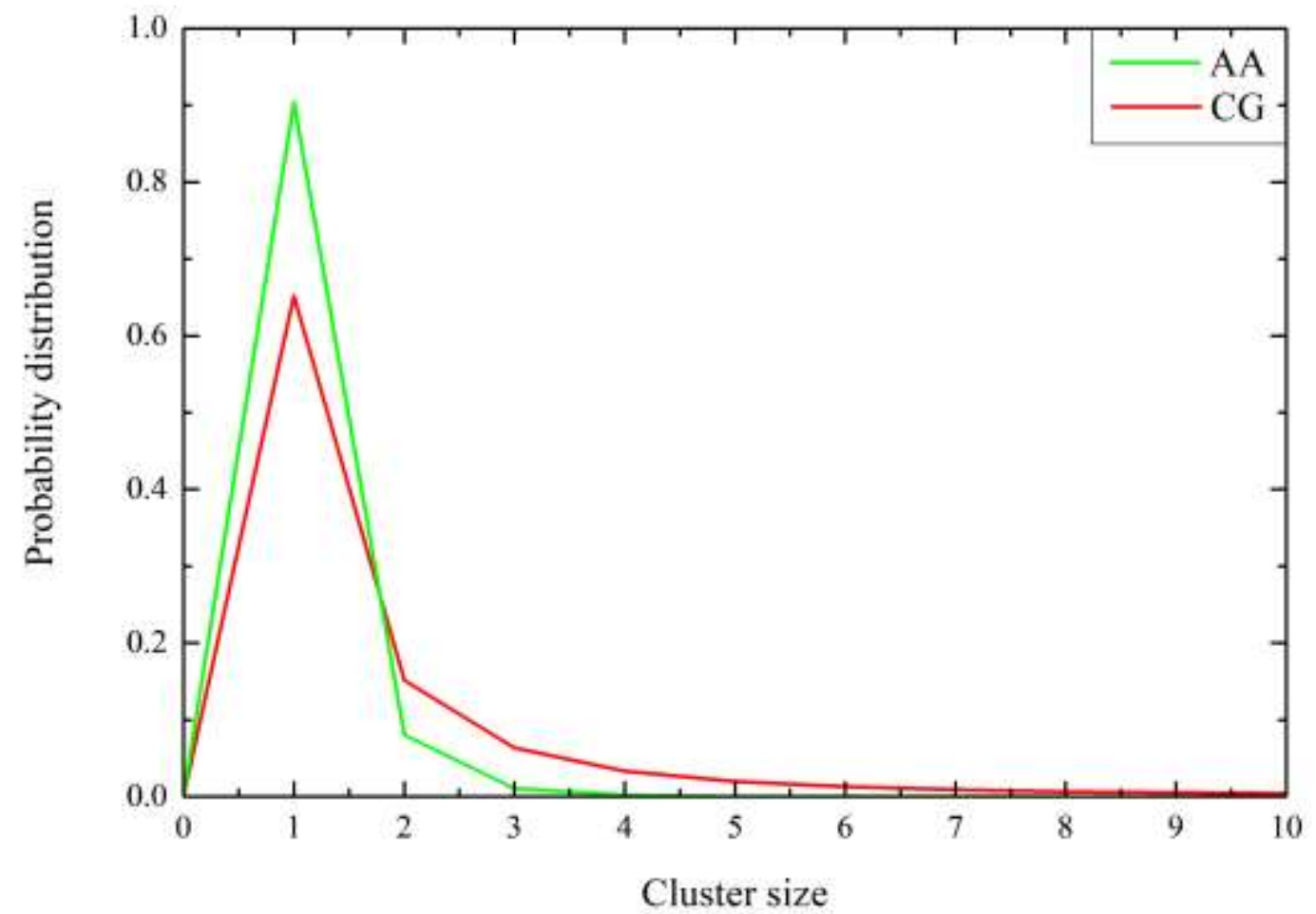

Figure S5. Probability distribution of the dodecanol cluster sizes by using the AA (green) and CG (red) method. 


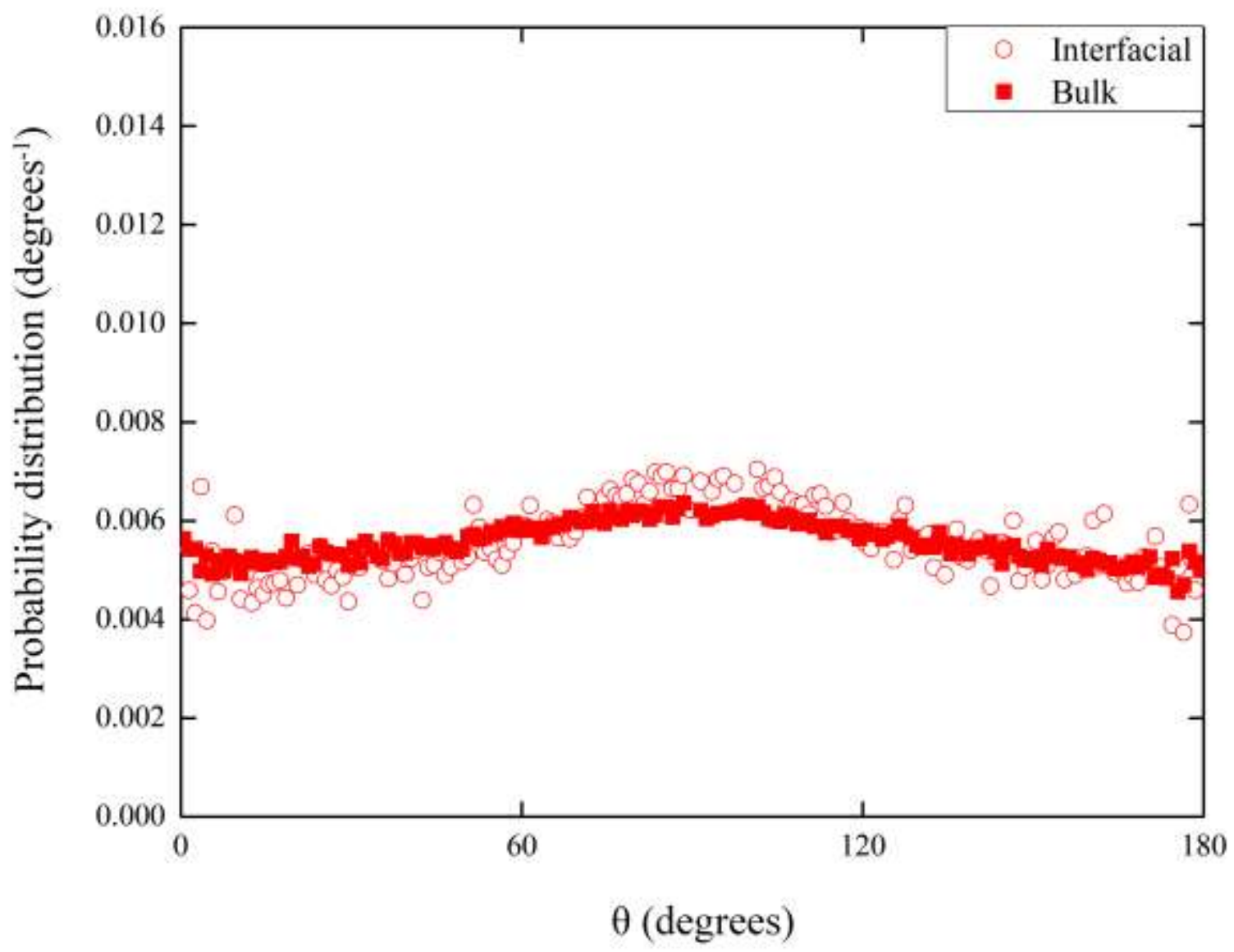

Figure S6. CG $n-\mathrm{C}_{28}$ probability distributions of the tilt angle $\theta$ formed between the end-to-end vector with respect to the $n-\mathrm{C}_{28}-\mathrm{H}_{2} \mathrm{O}$ mixture interface normal vector of chains in the bulk and at the interface at $473 \mathrm{~K}$ and $3.4 \mathrm{MPa}$. 

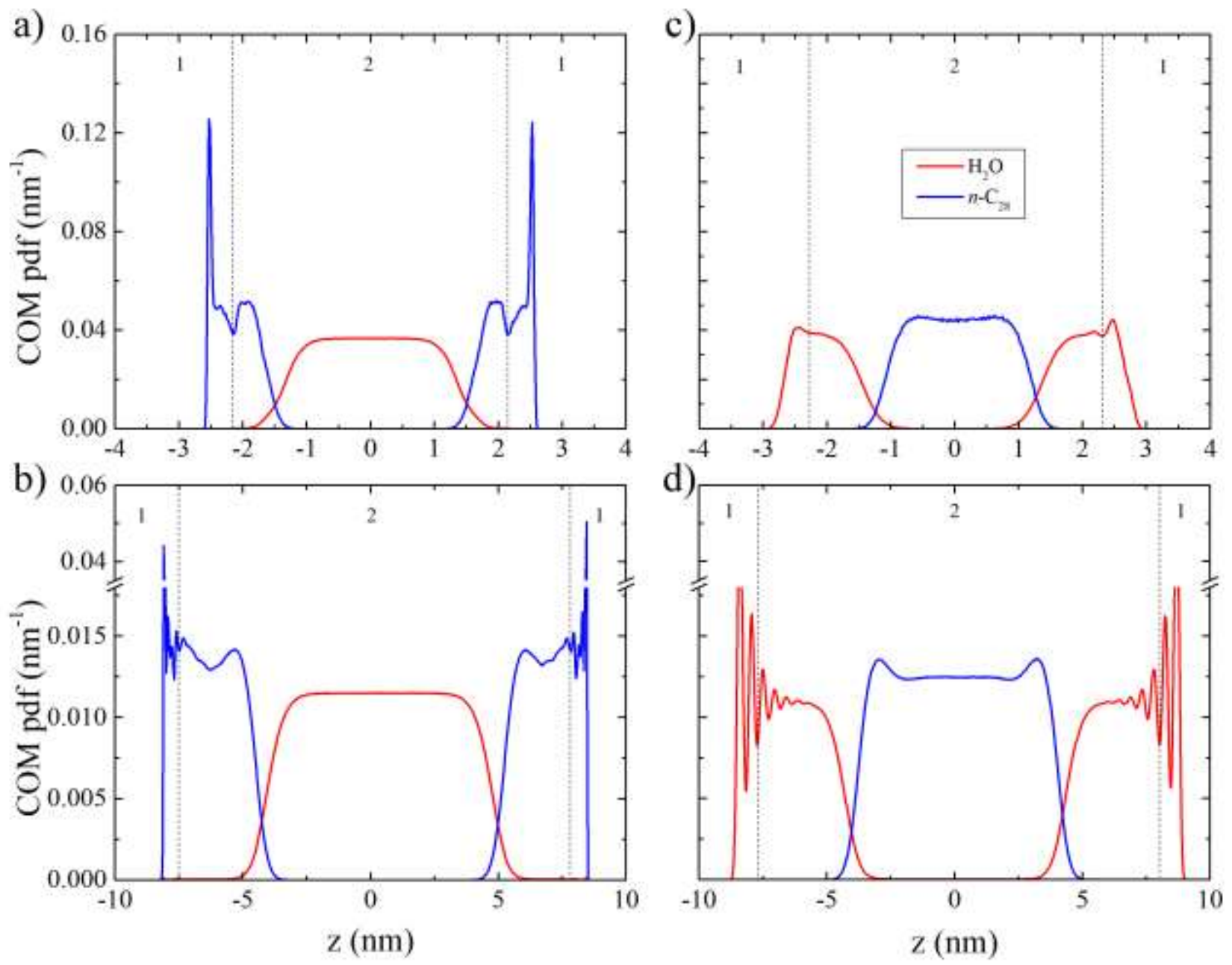

Figure S7. Calculated COM probability density functions (pdf) along the axis normal to the mesopore surfaces of the $n-\mathrm{C}_{28}-\mathrm{H}_{2} \mathrm{O}$ mixture in $\mathrm{G}$ and $\mathrm{GO}$, respectively, using AA (a and b) and CG (c and d) methods. The center of the pore corresponds to $z=0$. Partitioning of the pore into two discrete regions (namely 1 and 2 ) is depicted with vertical dashed lines. This partitioning was used for the calculation of the self-diffusion coefficients. 
a)
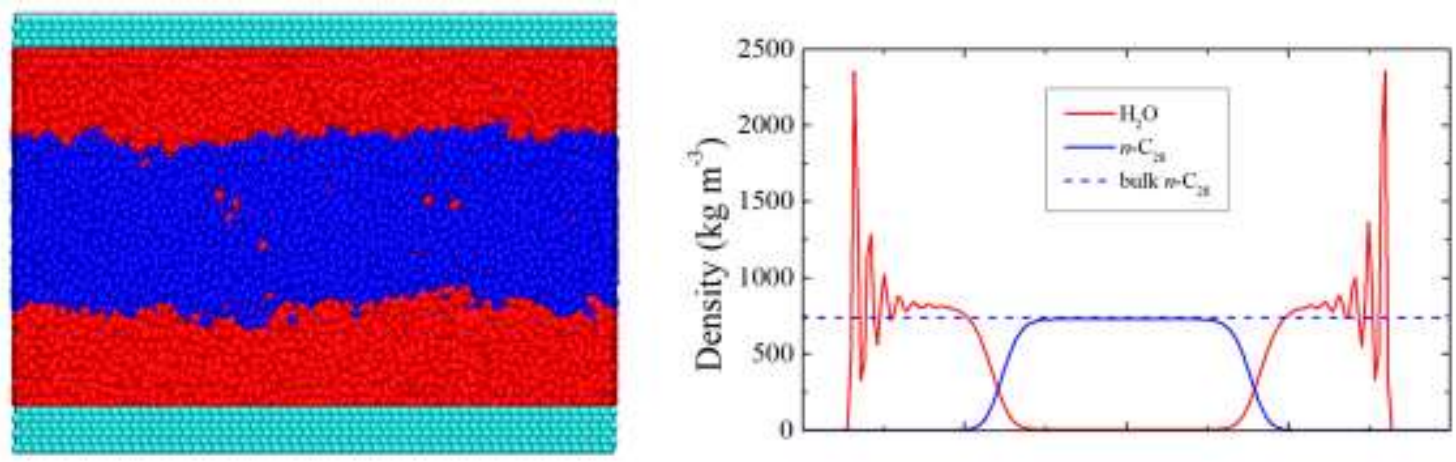

b)
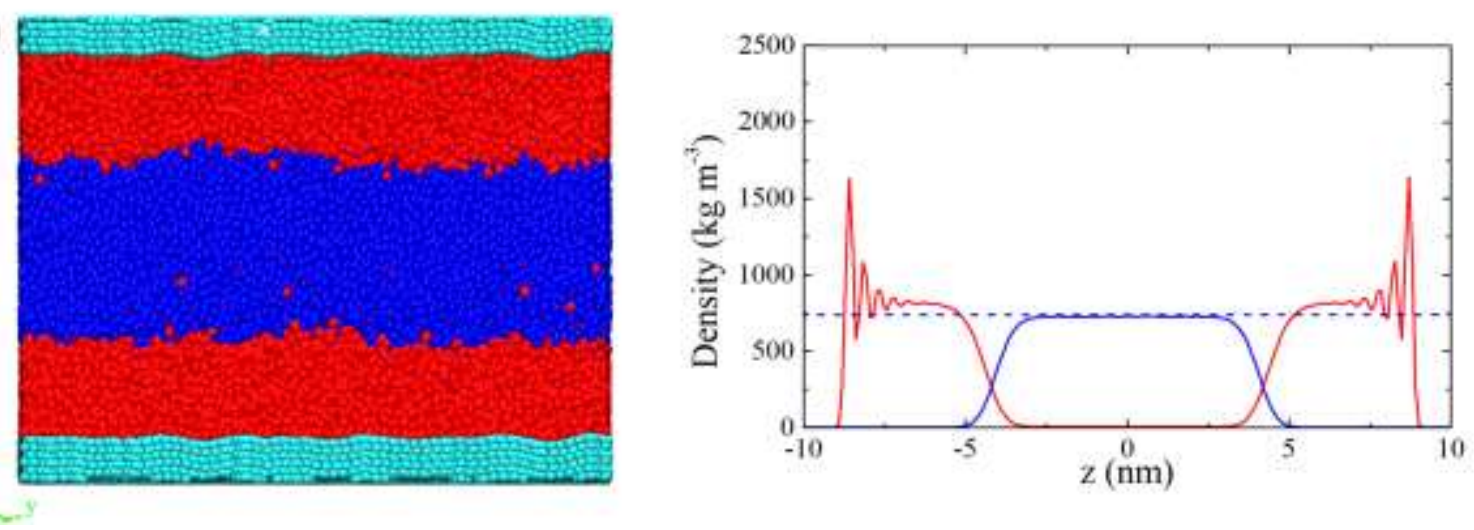

Figure S8. Calculated partial density profiles using a) completely flat and b) rippled GO pore surfaces. 


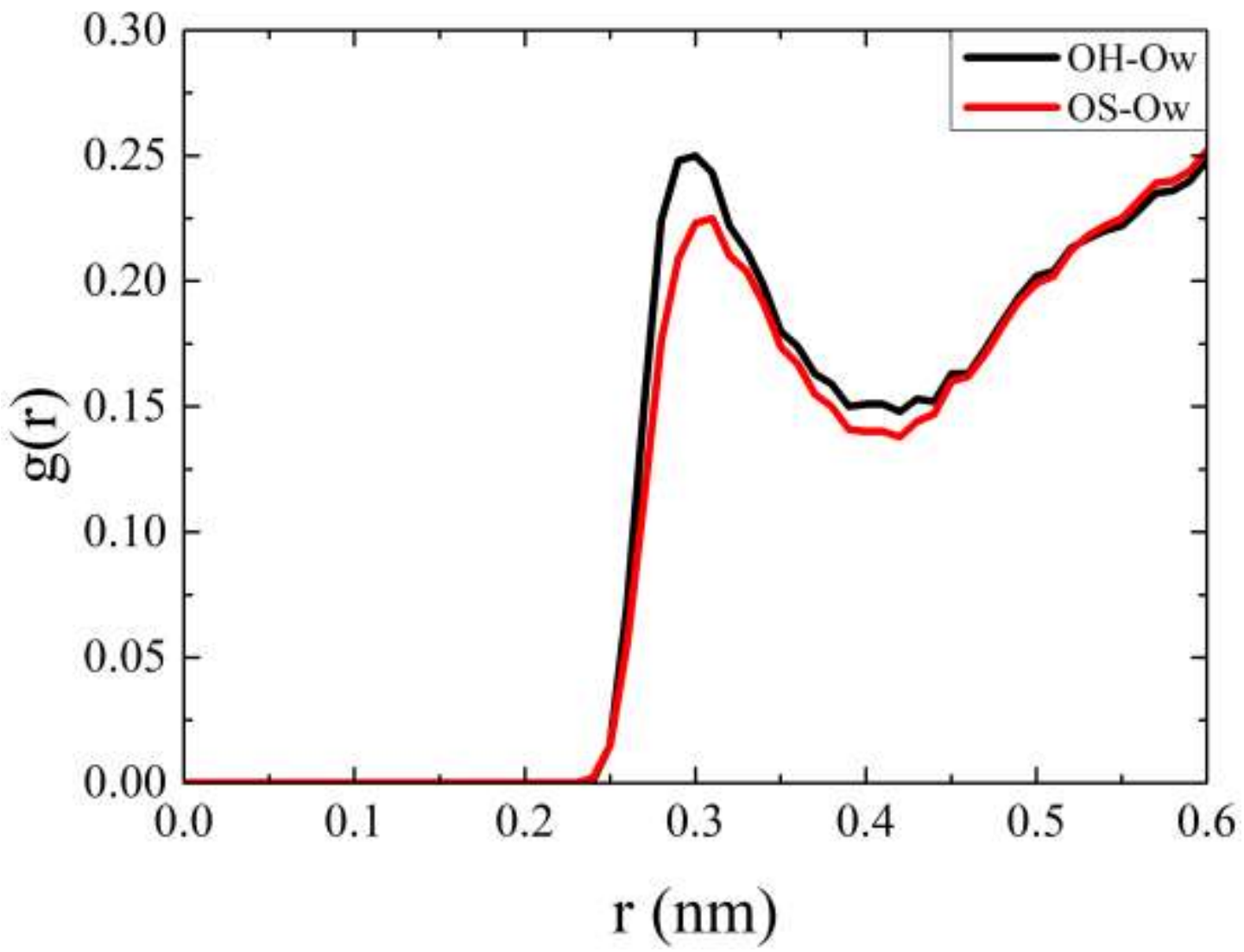

Figure S9. RDFs of the hydroxy (OH) and epoxy (OS) GO surface groups with water oxygen $(\mathrm{Ow})$. 


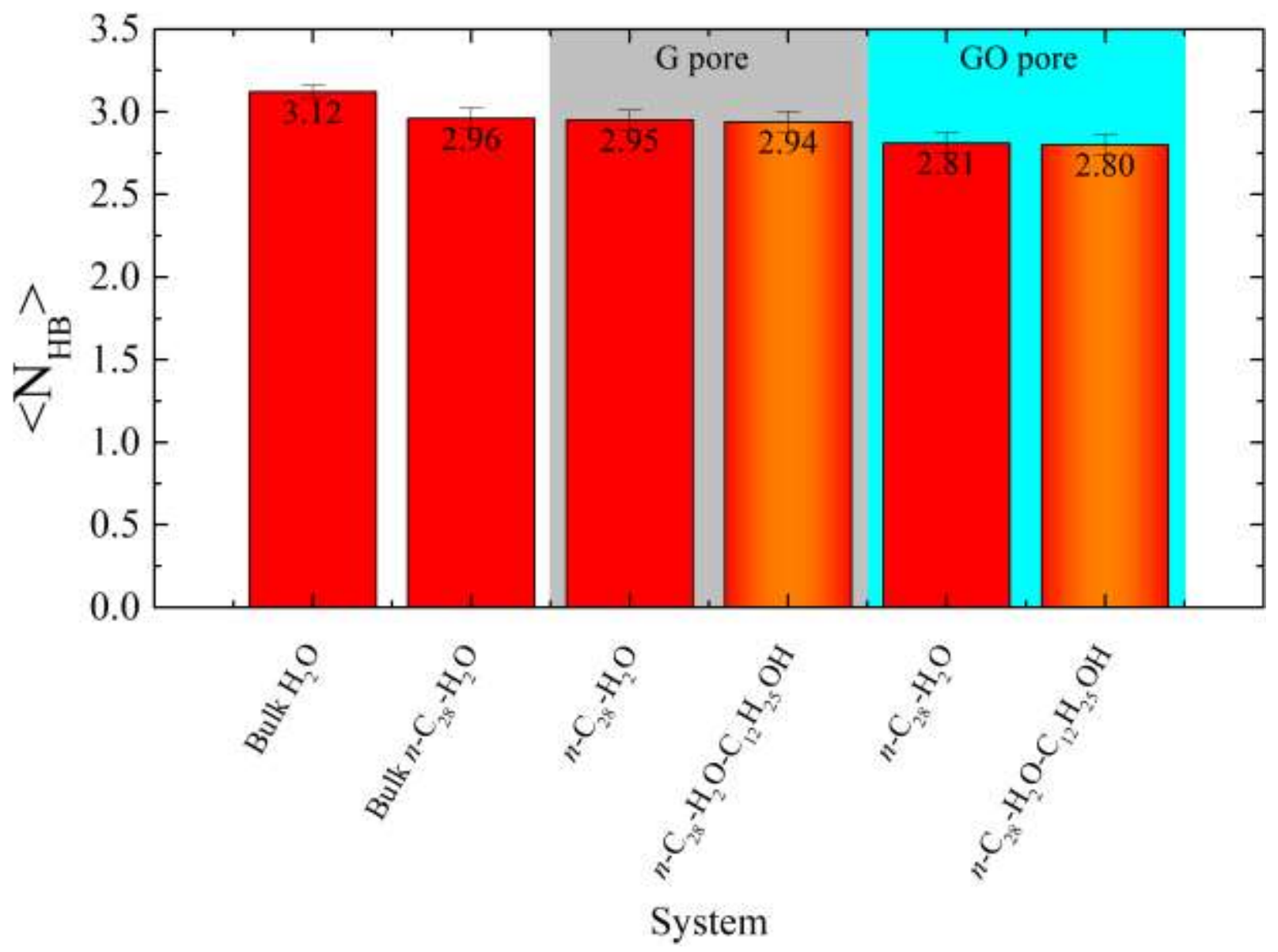

Figure S10. Calculated number of average hydrogen bonds (HB) per water molecule in all systems examined. HB analysis was performed over the last $50 \mathrm{~ns}(12,500$ frames) of the trajectories using geometric criteria, ${ }^{6}$ where a hydrogen bond is defined to exist if the donor-acceptor distance is less than the oxygen-oxygen RDF minimum distance (equal to $0.39 \mathrm{~nm}$ ) and simultaneously the hydrogen-donor-acceptor angle is less than $30^{\circ}$. 
a)

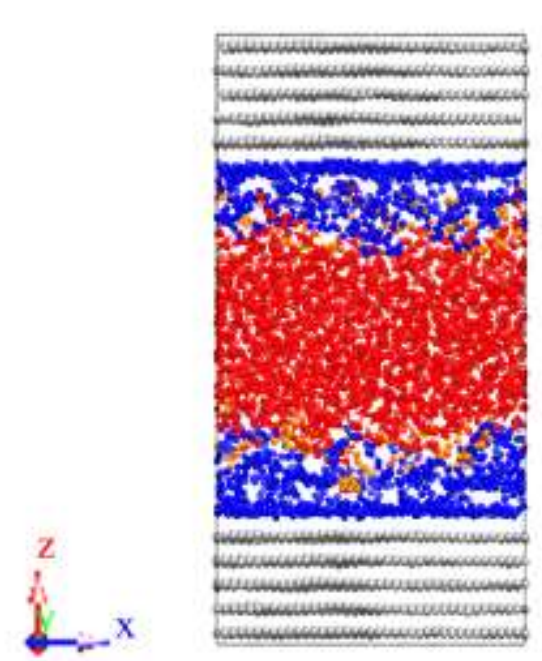

b)

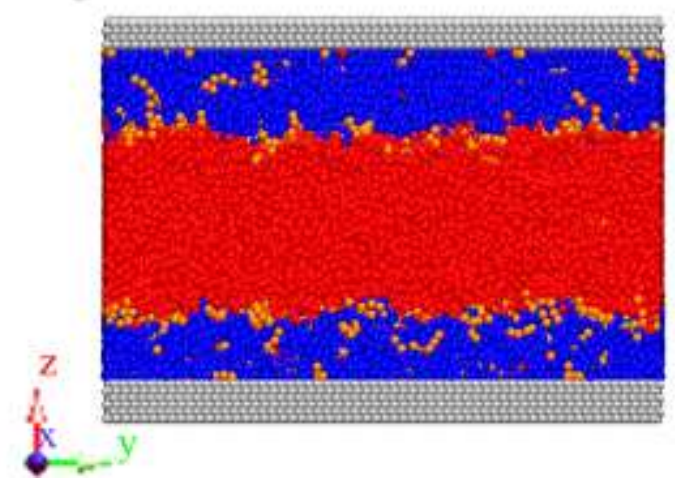

c)

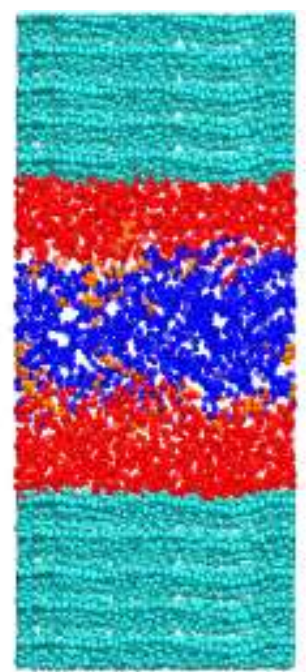

d)

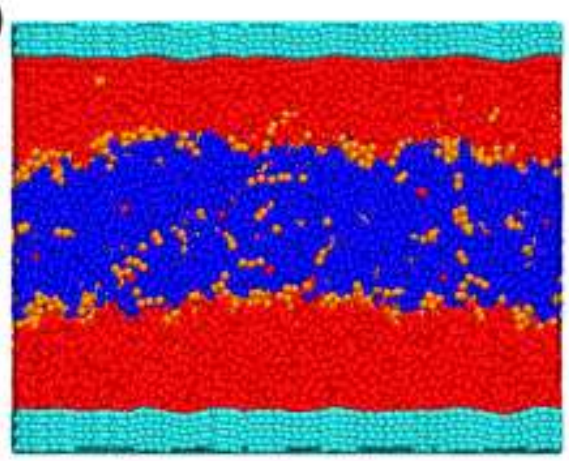

Figure S11. Equilibrated structures of the $n-\mathrm{C}_{28}-\mathrm{H}_{2} \mathrm{O}-\mathrm{C}_{12} \mathrm{H}_{25} \mathrm{OH}$ mixture in $\mathrm{G}$ (grey) and $\mathrm{GO}$ (cyan) pores, using AA (a and c) and CG (b and d) methods, respectively. Dodecanol molecules are colored in orange. 

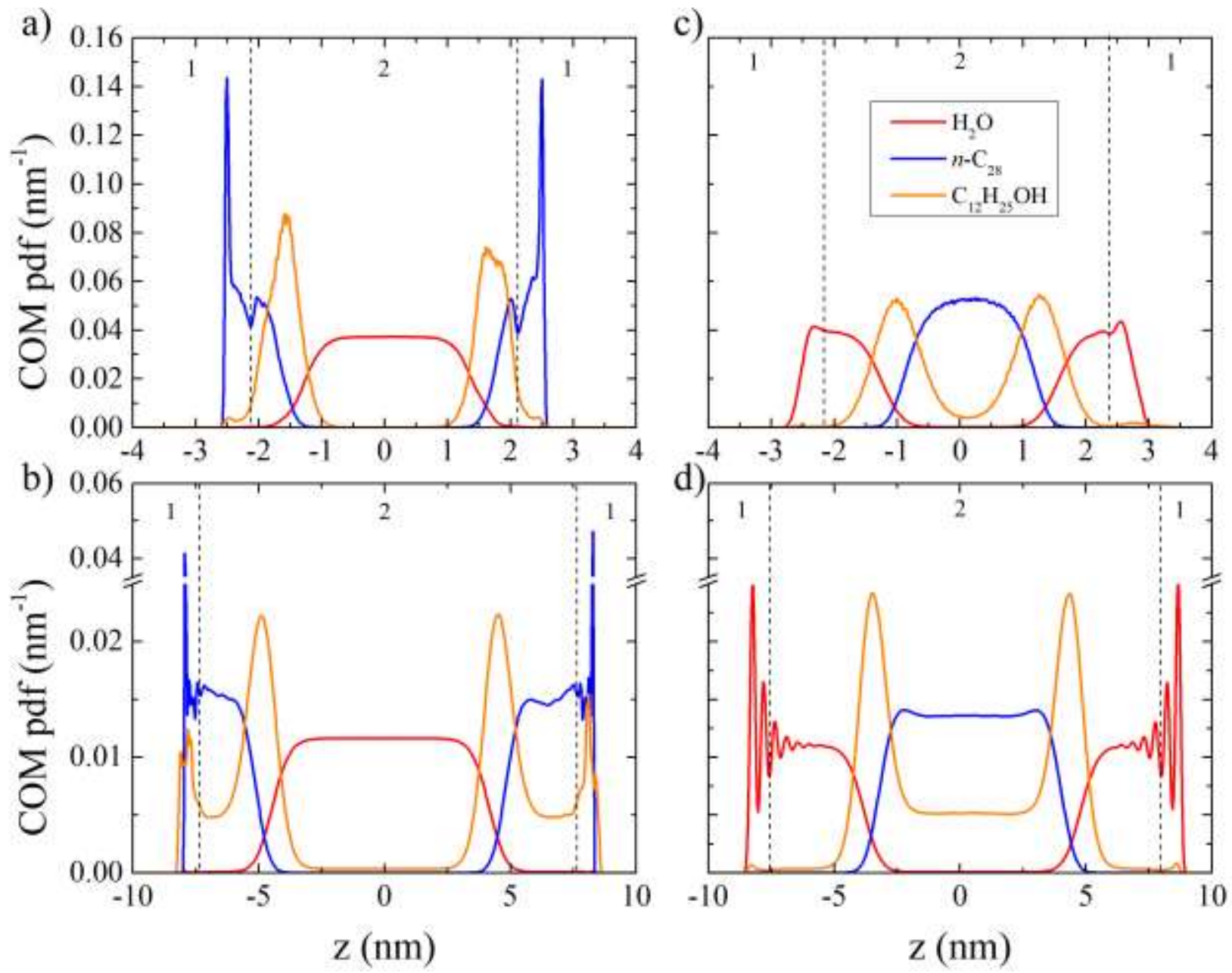

Figure S12. Calculated COM probability density functions (pdf) along the axis normal to the mesopore surfaces of the $n-\mathrm{C}_{28}-\mathrm{H}_{2} \mathrm{O}-\mathrm{C}_{12} \mathrm{H}_{25} \mathrm{OH}$ mixture confined in $\mathrm{G}$ and $\mathrm{GO}$, respectively, using AA (a and b) and CG (c and d) methods. 

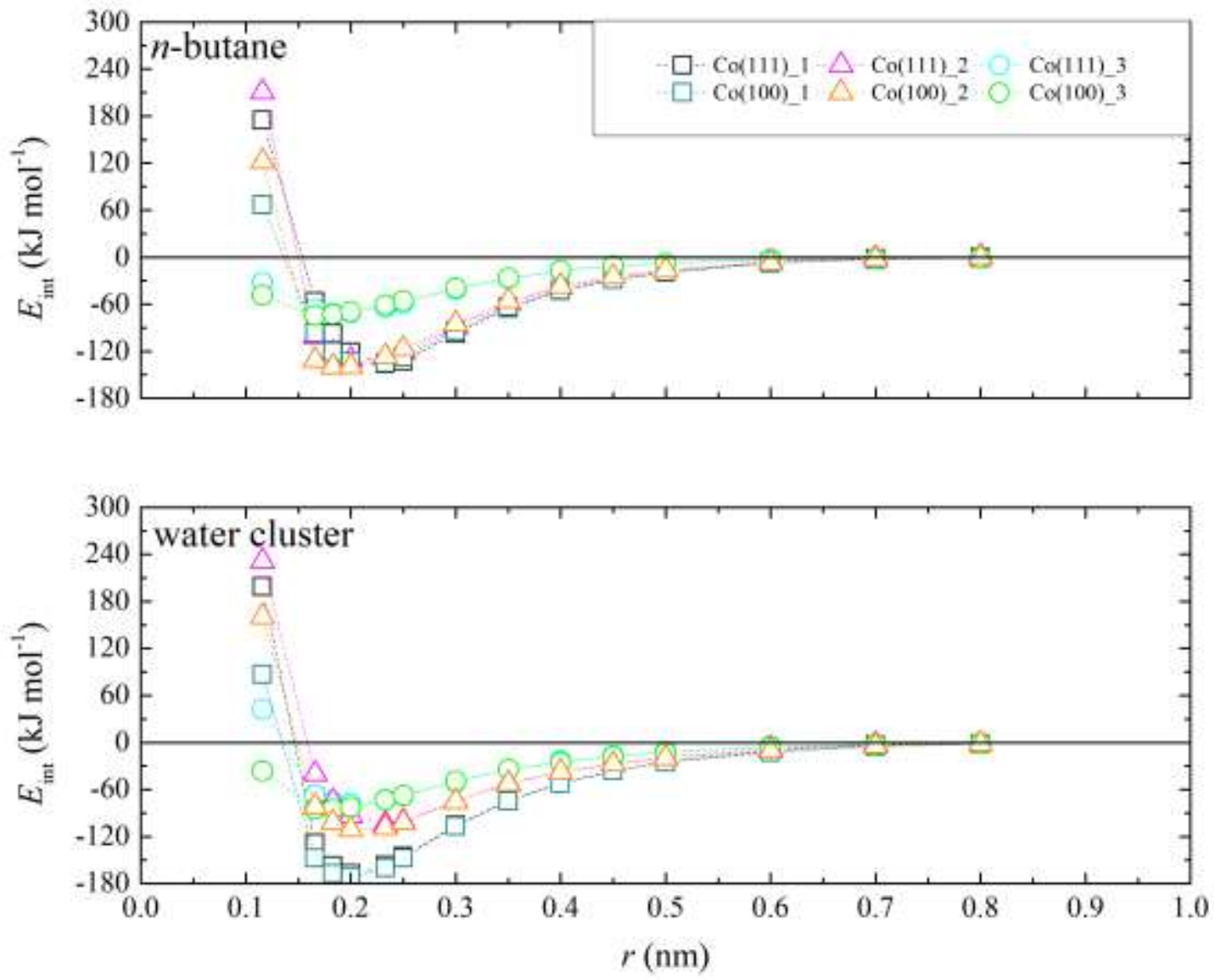

Figure S13. Interaction energies of the $24 \mathrm{Co}(100)$ and (111) atom clusters with $n$-butane and the four-molecule water cluster as a function of the closest molecular fragment atom (i.e. either $n$ butane or the four-water molecule cluster) at a given distance $r$ from the Co (111) and (100) surface. 


\section{References}

1. Daubert, T. E.; Danner, R. P., Physical and Thermodynamic Properties of Pure Chemicals: Data Compilation; Hemisphere Pub. Corp., New York, 2003.

2. Lemmon, E. W.; McLinden, M. O.; Friend, D. G., Thermophysical Properties of Fluid Systems. In NIST Chemistry Webbook, NIST Standard Reference Database Number 69, Linstrom, P. J.; Mallard, W. G., Eds. National Institute of Standards and Technology: Gaithersburg MD, 20899.

3. Danesh, A., PVT and Phase Behaviour of Petroleum Reservoir Fluids; Elsevier, New York, U.S.A., 1998.

4. Rostami, A.; Ebadi, H.; Arabloo, M.; Meybodi, M. K.; Bahadori, A., Toward Genetic Programming (GP) Approach for Estimation of Hydrocarbon/Water Interfacial Tension. $J$. Mol. Liq. 2017, 230, 175-189.

5. Larsen, A. H.; Mortensen, J. J.; Blomqvist, J.; Castelli, I. E.; Christensen, R.; Dulak, M.; Friis, J.; Groves, M. N.; Hammer, B.; Hargus, C.; Hermes, E. D.; Jennings, P. C.; Jensen, P. B.; Kermode, J.; Kitchin, J. R.; Kolsbjerg, E. L.; Kubal, J.; Kaasbjerg, K.; Lysgaard, S.; Maronsson, J. B.; Maxson, T.; Olsen, T.; Pastewka, L.; Peterson, A.; Rostgaard, C.; Schiotz, J.; Schutt, O.; Strange, M.; Thygesen, K. S.; Vegge, T.; Vilhelmsen, L.; Walter, M.; Zeng, Z. H.; Jacobsen, K. W., The Atomic Simulation Environment - a Python Library for Working with Atoms. J. Phys.: Condens. Matter 2017, 29, 273002.

6. Luzar, A.; Chandler, D., Effect of Environment on Hydrogen Bond Dynamics in Liquid Water. Phys. Rev. Lett. 1996, 76, 928-931. 